\title{
Developing and Implementing A System for Shipping Companies Comparison
}

Rawan Al-Theeb, Hessa Al-Tami, Hadeel Al-Johani, Asalah Al-Mutairi, Ibrahim Al-Marashdeh, Mutasem K. Alsmadi, Muneerah Alshabanah, Daniah Alrajhi

Department of Management Information Systems, College of Applied Studies and Community Service, Imam Abdurrahman Bin Faisal University, Al-Dammam, Saudi Arabia

\begin{abstract}
Information-intensive Web services such as shipping comparison sites have recently been gaining popularity. However, most users including novice shoppers have difficulty in browsing such sites because of the massive amount of information gathered and the uncertainty surrounding Web environments. The aim of this research is to design a system which is called Shohnati to perform all procedures related to the order of shipment, and to store and process all information relating to customers or shipping companies in a database. Through this research, the customers will be able to order the shipment more easily by providing a complete comparison between the shipping companies, request the shipment from the preferred company's site, follow the shipment, and follow the latest offers of companies on our site. The proposed system was developed using the Unified Modeling Language (UML) and Visual Studio-ASP.NET programming language.
\end{abstract}

Keywords : Shipping Companies, Software Engineering and Unified Modeling Language.

\section{INTRODUCTION}

The technological development in all fields has led to the development of systems, and the efforts of companies and institutions to computerize their systems in line with the requirements of this era, which has facilitated the work and services provided by these companies and institutions and increased the efficiency of the systems [1]. In addition, new communication technologies have changed the manner in which individuals access and acquire information from various information sources [1, 2]. Many Web sites and Web services are based on the flux of information convergence and Web users enjoy a wide access to abundant information from various sources through [3].

However, the costumers may have some difficulty in combining, transforming, and processing massive amounts of gathered information, especially when comparing prices which may result in irrelevant search results, fraudulent transactions, and dispersed information [1, 3, 4]. Therefore, many users may become disoriented and face worsening problems of information overload and uncertainty when browsing information-intensive Web sites [5].

Many shipping customers are complaining about the expensive delivery rate, delays in arrival and lack of insurance, technical difficulties in using shipping companies applications, lack of an urgent and secure shipping manner. Also the emergence of the huge need to search and find the right shipping company to deliver the shipments in less time, less cost and safe way, and to provide multiple options to suit the user and keep pace with technological development and e-operation [1]. 
This research aims to assist the customers to choose the shipping company, and to provide integrated services and high quality for all their needs as fast as possible. For example when comparing prices comparison site providing online shoppers with opportunities to acquire a wide range of information on various products. It is well known that a price comparison site (PCS) can help online shoppers reduce the amount of time or effort required when searching for products online [1,6-9]. Shipped is a website that deals with shipping services and serves as the connection between the various shipping companies and customers, allowing the owners of shipments (customers) to get the best price through the trade-off between companies and to choose what suits them with the least effort, and a sure profit for companies when competing to provide the best to the customers.

\section{RELATED WORKS}

\section{- Aramex}

The Aramex App allows all Aramex customers around the world to track delivery, monitor shipment progress and manage their account, addresses and delivery details. With the app costumers can manage their entire Aramex delivery experience using their phones [10]. The disadvantages of this application are the high shipping prices, no insurance is available on the shipment, delayed arrival of shipments on time and the application does not support Arabic.
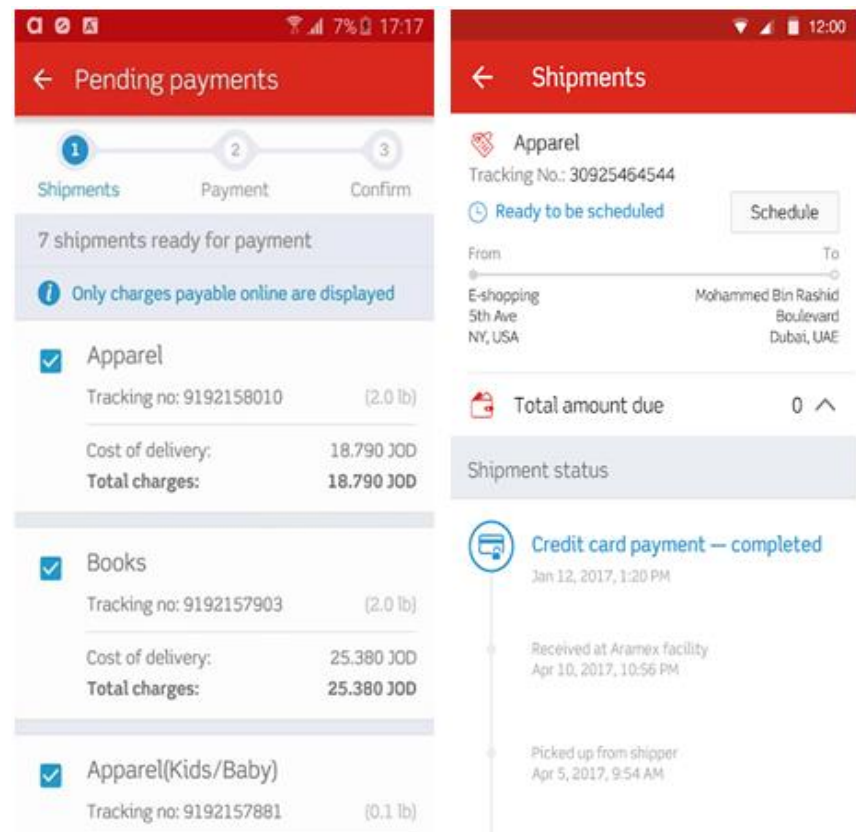

Figure 1 : an example of shipment monitor interface via Aramex application

\section{- Naqel Express}

Naqel focuses its services on providing logistics solutions for all individual customers or companies and provides internal and international shipping services. Naqel application is tailored to the meet the customer's needs:

- Track shipment status

- Schedule a pickup

- Shop on-line using our e-com partners

- Share feedback with our Customer Service Center

- Know about our products, tariffs and delivery times 


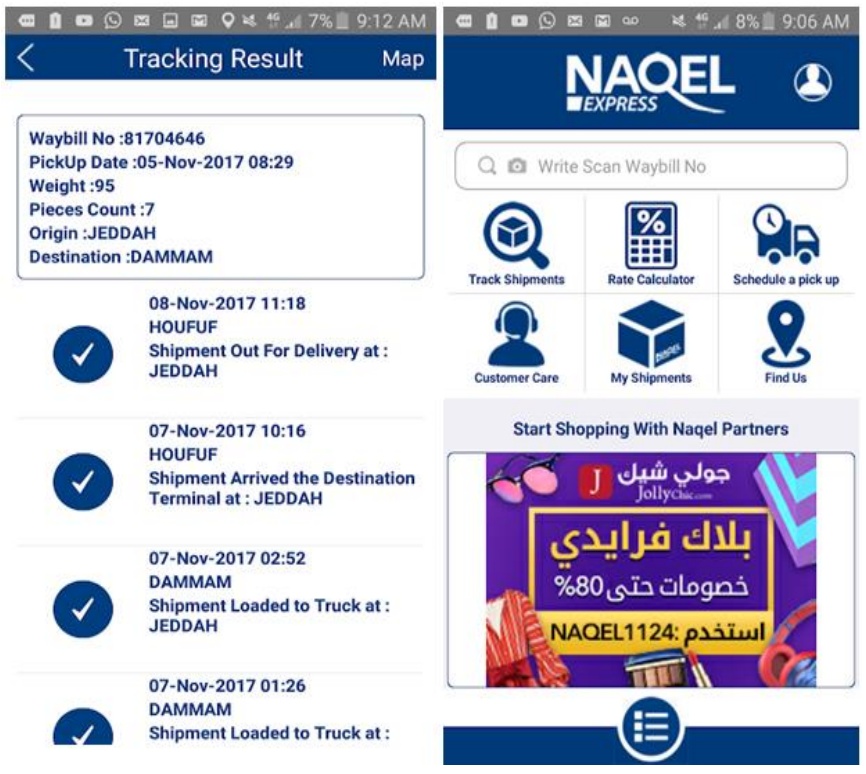

Figure 2 : An example of shipment monitor interface via Naqel Express application [11]

\section{- SMSA Express}

SMSA Express is a market leader in the courier industry. It boasts a solid business platform through which it have provided services to tens of thousands of businesses and individuals in the Saudi market since 1994. Since commencing business, SMSA Express has developed a range of services, including international and domestic express transportation, road, sea and airfreight, customs clearance, ecommerce solutions, special services for the health care sector, special delivery channel, mailroom management and many other services that qualify SMSA Express as the ideal logistics partner for prominent Saudi companies.

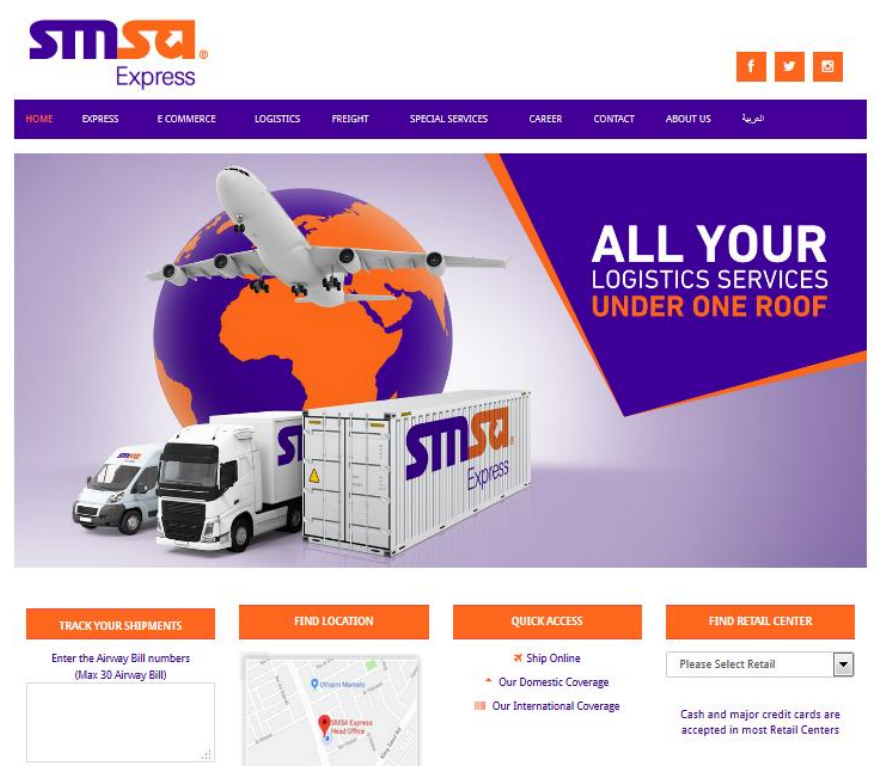

Figure 3: SMSA Express interface [12].

The technological revolution influenced everything [13-33], even the methods that aim to improve the shipping companies comparison through an electronic system. Today, the use of Artificial Intelligence (AI) algorithms is expansive, particularly in providing solutions to challenging problems including patterns recognition and retrieval of information [28, 34-50], image segmentation [13, 14, 24, 51-56], analysis of medical images [57-61], Learning Management System [62-87], nurse rostering problem [88], Healthcare Monitoring system [27, 89], as well as prediction of river flow [90-92]. Accordingly, many researchers have used the Artificial Intelligence as an effective tool for shipping companies' comparison systems [93, 94].

\section{SYSTEM ANALYSIS}

The UML has been developed to offer a standardized notation to define Object Oriented Models. However, to effectively apply the UML notation, it must be employed with an Object-Oriented Analysis and Design method [95-99]. Object-Oriented analysis and design (OOAD) refers to a group of methodologies to produce business component based software. The 
methodology summaries the life cycle of system development identifying the deliverables and tasks in an object-oriented project [100]. Using a combination of UML notation and process, the life cycle of system development can be reduced, the system can be easily maintained, and the modules reusability can be improved.

The UML is a language used to specify, visually model [101], and document the artifacts of an ObjectOriented system under development. It denotes a number of ideas unification from various methods. UML is used in the system design to improve its reusability and maintainability. Object-oriented analysis methods offer class, use case, state chart, sequence and other diagrammatic notations for modeling [102]. UML has been employed effectively in many projects for modeling different requirements and architectures [101].

\subsection{Use Case Diagram}

According to the Bhuiyan et al., [103], a use case is "the specification of a set of actions performed by a system, which yields an observable result that is typically, of value for one or more actors or other stakeholders of the system". The Use Case diagram provides a visual view of sequence of steps to achieve a task and describes the use of a system by the actors related to it $[21,22,25,26,31,104]$. These actors are any external elements that interact with the system. The interactions between the system and various actors provide a way for the developers to come to a common understanding with the systems' end users and domain experts [84, 98, 101, 105, 106]. Use Cases also help to validate the proposed system architecture and to verify the system as it evolves during development. Figure 4 shows the use case diagram for the proposed system.

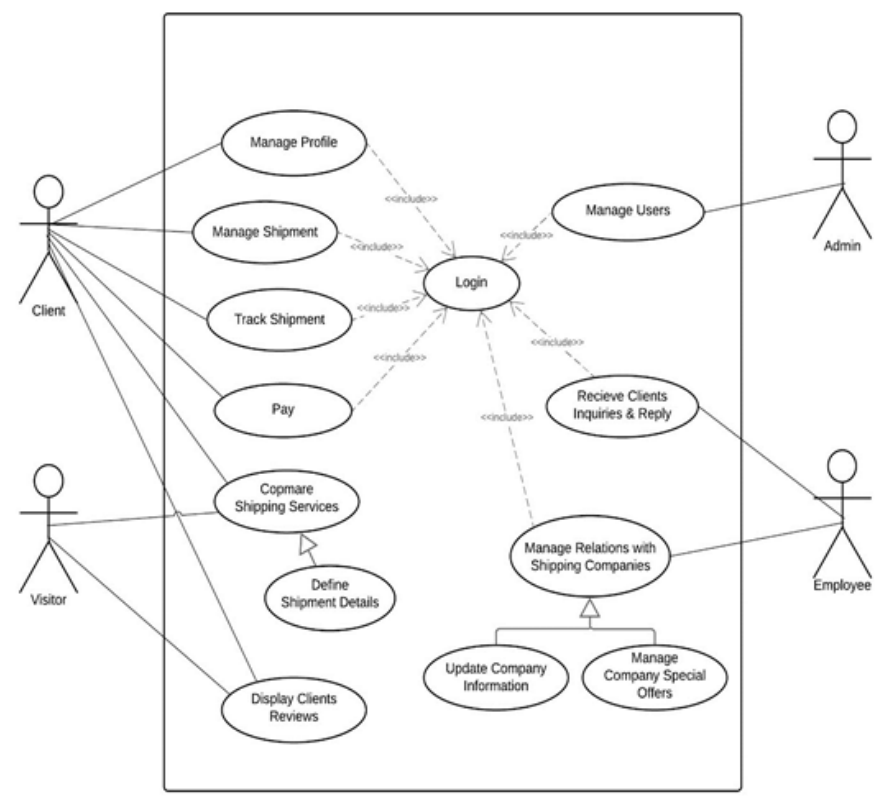

\subsection{Context Diagram}

The Context Diagram (CD) is used to establish the boundaries and context of the system to be modeled; which things are outside and inside of the system being modeled, and what are the relationships of these external entities with the system. CD sometimes called a level 0 data-flow diagram is drawn in order to clarify and define the boundaries of the software system. It identifies the information flows between the external entities and system [107]. Figure 5 shows the Context Diagram for the proposed system.

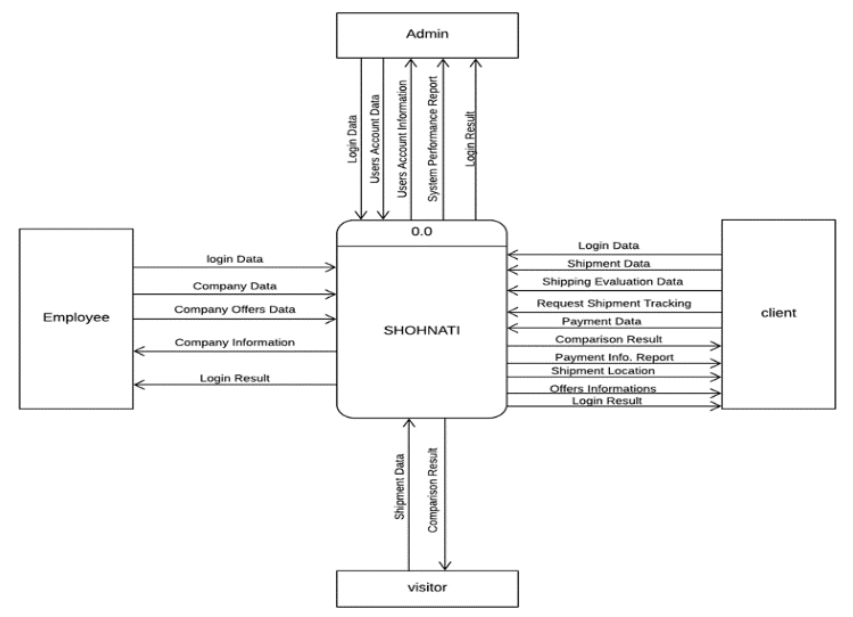

Figure 5 : Context Diagram for the proposed system. 


\subsection{Entity Relationship Diagram (ERD)}

The ERD provides a way of graphically representing the logical relationships between entities in order to create a database schema to persist those entities [21, 22, 25, 26, 30]. The ER Model was first proposed by
Peter Chen of Massachusetts Institute of Technology (MIT) in the 1970s. The ERD of the system is involved seven entities (tables) which are customer, consult, adviser and system administrator. Figure 6 shows the ERD for the proposed system.

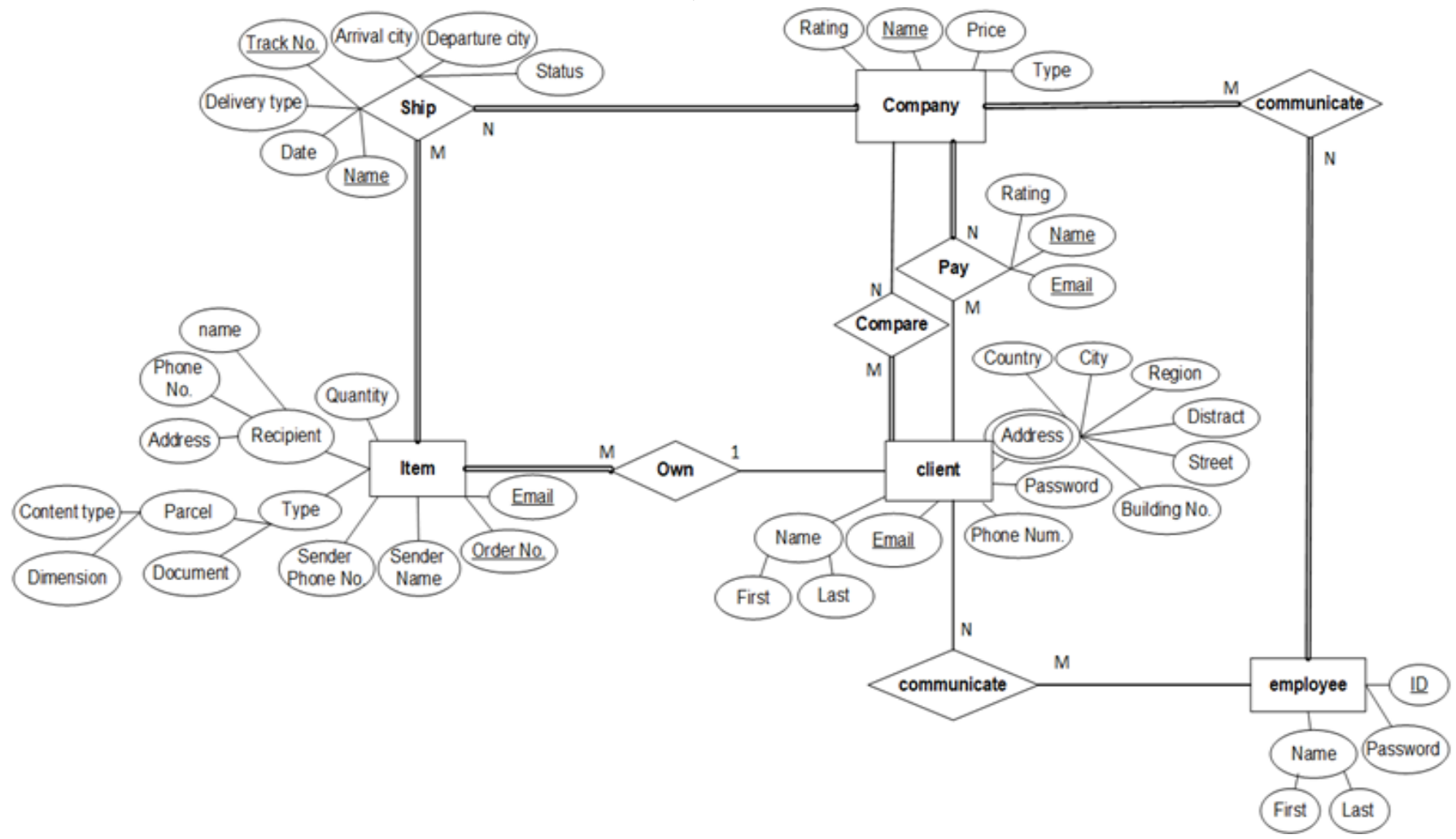

Figure 6: ERD for the proposed system

\section{DATABASE TESTING AND CONSTRUCTION}

The database testing is essential for finding errors that can affect the consistency, security, performance and reliability of the system, and it is important for system validation against the user specified requirements [108, 109]. Structured Query Language (SQL) was used for database implementation. The tables below are examples of the created tables.

Table 1: Shipping table

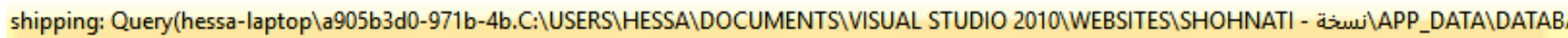

\begin{tabular}{|l|l|l|l|l|l|l|l|}
\hline & trackno & depart & arrival & delivery_type & date & weight & status \\
\hline & 234567892345678 & khuber & ryiadh & express & $06-04-2019$ & 0.5 & Deliverd \\
\hline & 345678934567899 & dammam & Ryiadh & Regular & $07-04-2019$ & 2 & Deliverd \\
\hline & 768905432167548 & khuber & jeddah & Regular & $14-04-2019$ & 4 & Deliverd \\
\hline & 457348901237659 & dammam & makkah & regular & $14-04-2019$ & 2 & Deliverd \\
\hline & 324567890123456 & khuber & jeddah & express & $20-04-2019$ & 1.5 & Deliverd \\
\hline & NULL & NULL & NULL & NULL & NULL & NULL & NULL \\
\hline
\end{tabular}


Table 2: Item table

\begin{tabular}{|c|c|c|c|c|c|c|c|c|c|c|}
\hline & order_no & quantity & type & content_type & dimension & sender_name & receipient_name & receipient_pho... & receipient_address & sender_phone \\
\hline & 1111 & 1 & parcel & TV & $55 \times 44$ & hessa & Arwa & 0565759319 & Ryiadh,Olya-street 10, building 34 & 0546778083 \\
\hline & 1114 & 1 & parcel & & $33 \times 50$ & hadeel & khaled & 05222222222 & jeddah,street20,7896 & 0543114450 \\
\hline & 1115 & 3 & document & & & rawan & norah & 0533333333 & makkah-street 10 & 0503652254 \\
\hline & 1116 & 1 & parcel & clothes & & hessa & osamah & 0522222222 & jeddah-street $7 \mathrm{~b}$ & 0546778083 \\
\hline & 1124 & 2 & document & & & hadeel & Reem & 0511111111 & Ryiadh-street20 & 0543114450 \\
\hline p* & NULL & NULL & NULL & NULL & NULL & NULL & NULL & NULL & NULL & NULL \\
\hline
\end{tabular}

Table 3: Shipping Companies table

company: Query(hessa-laptopla905b3d0-971b-4b.C:IUSERSIHESSAIDOCUMENTSIVISUAL STUDIO 2010IWEBSITESISHOHNA

\begin{tabular}{|c|c|c|c|c|c|}
\hline name & weight & price & type & imaqe & rating \\
\hline Aramex & 0.5 & 38 SR & Express & & 4 star \\
\hline Aramex & 0.5 & $18 \mathrm{SR}$ & Regular & NULL & 4 star \\
\hline Aramex & 2 & $45 S R$ & Express & NULL & 4 star \\
\hline Aramex & 2 & $25 \mathrm{SR}$ & Regular & NULL & 4 star \\
\hline Aramex & 5 & 52 SR & Express & NULL & 4 star \\
\hline Aramex & 5 & $32 \mathrm{SR}$ & Regular & NULL & 4 star \\
\hline Aramex & 10 & $59 \mathrm{SR}$ & Express & NULL & 4 star \\
\hline Aramex & 10 & 39 SR & Regular & NULL & 4 star \\
\hline Aramex & 15 & $66 \mathrm{SR}$ & Express & NULL & 4 star \\
\hline Aramex & 15 & $46 \mathrm{SR}$ & Regular & NULL & 4 star \\
\hline Aramex & $>15$ & 71.75 SR & Express & NULL & 4 star \\
\hline Aramex & $>15$ & 51.75 SR & Regular & NULL & 4 star \\
\hline $\mathrm{DHL}$ & 0.5 & 42 SR & Express & NULL & 5 star \\
\hline $\mathrm{DHL}$ & 0.5 & $16 \mathrm{SR}$ & Regular & NULL & 5 star \\
\hline $\mathrm{DHL}$ & 2 & $52.50 \mathrm{SR}$ & Express & NULL & 5 star \\
\hline $\mathrm{DHL}$ & 2 & $26.50 \mathrm{SR}$ & Regular & NULL & 5 star \\
\hline $\mathrm{DHL}$ & 5 & 73.50 SR & Express & NULL & 5 star \\
\hline
\end{tabular}

\section{Interface Design}

The goal of user interface design is to make the user's interaction as simple and efficient as possible, in terms of accomplishing user goals. The programming language utilized in this work is Visual StudioASP.NET programming language. The programming language is chosen relying on the languages features which make them more suitable for this work. The figures 7, 8 and 9 below are examples of the proposed system interfaces.

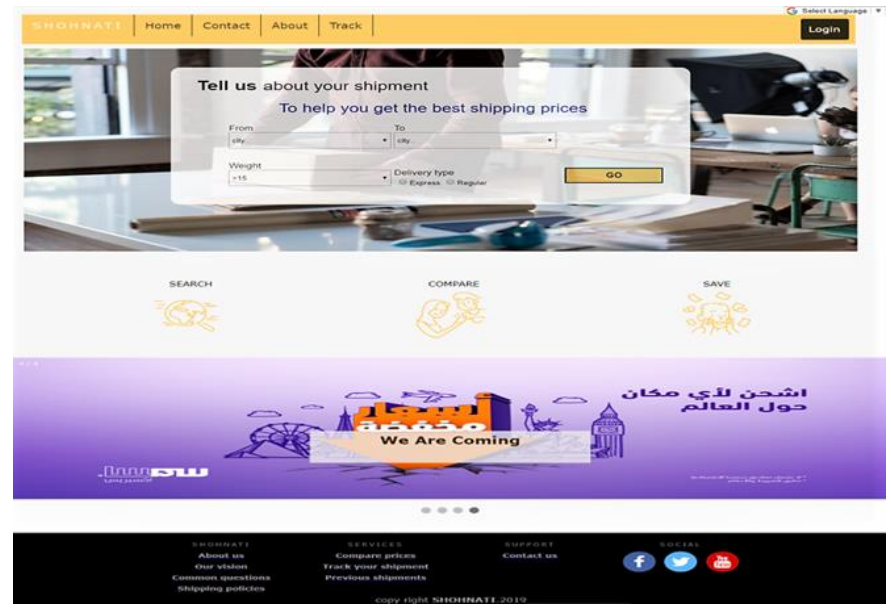

Figure 7: Main interface. 


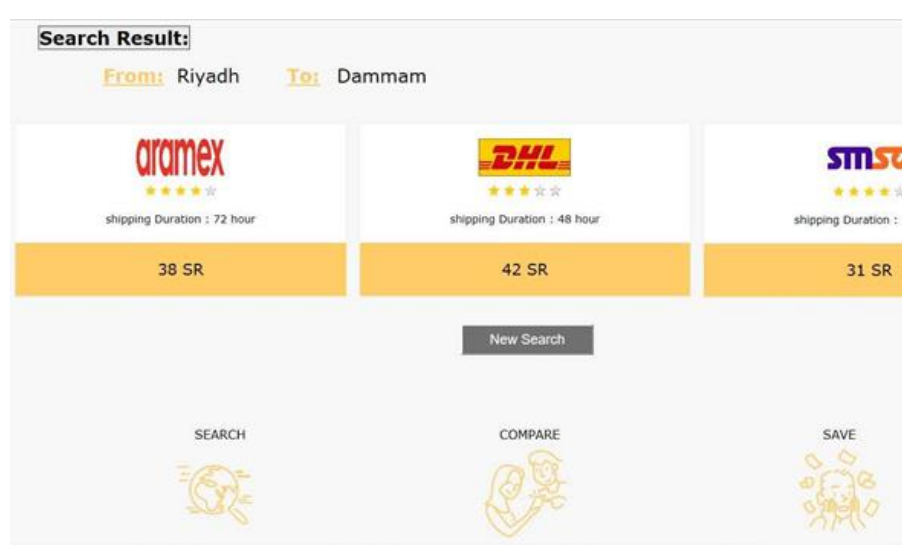

Figure 8: Comparison interface

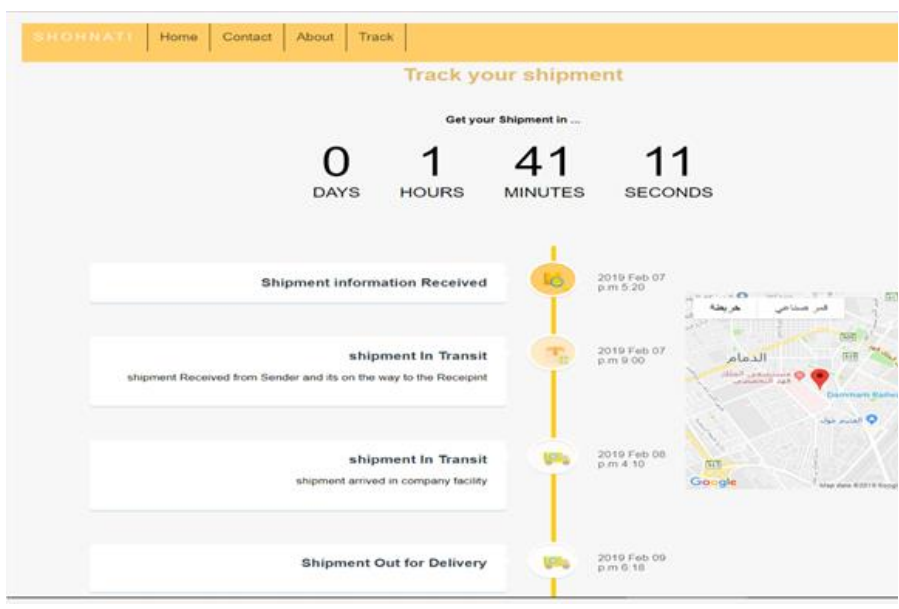

Figure 9: Shipment tracking interface

\section{Discussion}

This stage highlights the usability of the proposed system. During this stage, the system is evaluated while user satisfaction is ensured. Test was executed on the proposed system by running it on Mozilla Firefox and Internet Explorer using the local host server. For evaluation purpose, 20 students from College of Applied Studies and Community Service at Imam Abdurrahman Bin Faisal University (IAU) were invited to use the prototype. The students were first briefed on the prototype's usage and the user interface. Then, the students tested the system, and answered the survey questionnaire consisting of 10 items formulated to gauge the level of user satisfaction. The usability of the proposed system was also determined. The result as well as the level of usability of the system according to the feedback provided by 20 students can be referred in figure 10 . As can be construed by the result, a significant amount of users agrees that system is practical, useful and fulfill the project's primary objective.

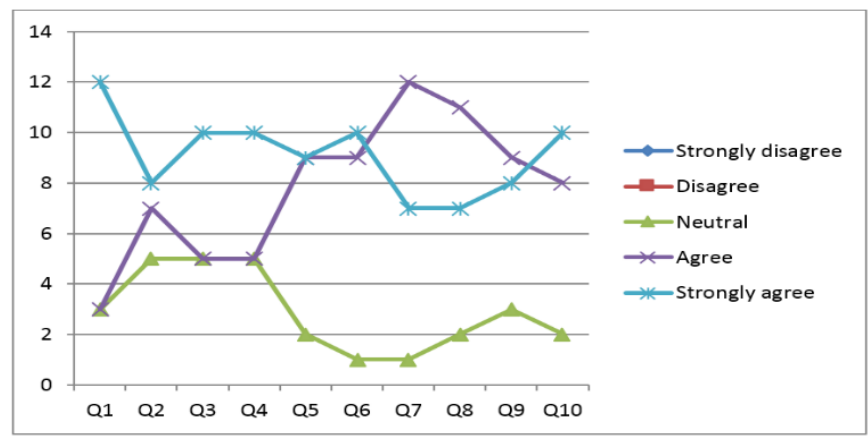

Figure 10: collected data results from the 20 students

\section{VII.Conclusion}

In this research, Shohnati system was designed and developed to improve the shipping services of various shipping companies. The proposed helps the user to assist the customers to choose the shipping company, and to provide integrated services and high quality for all their needs as fast as possible system can be developed to include local and international areas. The proposed system was developed using the Unified Modeling Language (UML) and Visual Studio-ASP.NET programming language.

\section{References}

[1]. Kim, J.W. and S.H. Ha, Price comparisons on the internet based on computational intelligence. PloS one, 2014. 9(9): p. e106946.

[2]. Walther, J.B., C.T. Carr, and S.S.W. Choi, Interaction of interpersonal, peer, and media influence sources online: A research agenda for technology convergence, in A networked self2010, Routledge. p. 25-46.

[3]. Zhang, Y.-Q. and T. Lin. Computational web intelligence (CWI): synergy of computational 
intelligence and web technology. in 2002 IEEE World Congress on Computational Intelligence. 2002 IEEE International Conference on Fuzzy Systems. FUZZ-IEEE'02. Proceedings (Cat. No. 02CH37291). 2002. IEEE.

[4]. Hong, S.-Y., J.-W. Kim, and Y.-H. Hwang, Fuzzy-semantic information management system for dispersed information. Journal of Computer Information Systems, 2011. 52(1): p. 96-105.

[5]. Castellano, G., A.M. Fanelli, and M.A. Torsello, Computational Intelligence techniques for $\mathrm{Web}$ personalization. Web Intelligence and Agent Systems: An International Journal, 2008. 6(3): p. 253-272.

[6]. Baye, M.R., J. Morgan, and P. Scholten, Price dispersion in the small and in the large: Evidence from an internet price comparison site. The Journal of Industrial Economics, 2004. 52(4): p. 463-496.

[7]. Haynes, M. and S. Thompson, Price, price dispersion and number of sellers at a low entry cost shopbot. International Journal of Industrial Organization, 2008. 26(2): p. 459-472.

[8]. Lim, G.G., et al., Rule-based personalized comparison shopping including delivery cost. Electronic Commerce Research and Applications, 2011. 10(6): p. 637-649.

[9]. Vachon, F., Can online decision aids support non-cognitive web shopping approaches? International Journal of Business and Management, 2011. 6(10): p. 16-27.

[10]. Aramex,

Aramex

App. https://www.aramex.com/aramex-app, 2019.

[11]. Preview, A.S., Naqel Express. https://apps.apple.com/sa/app/naqelexpress/id12 97949272, 2019.

[12]. SMSA-Express, http://www.smsaexpress.com/index.html\#. 2019.
[13]. Alsmadi, M.k., et al. Performance Comparison of Multi-layer Perceptron (Back Propagation, Delta Rule and Perceptron) algorithms in Neural Networks. in 2009 IEEE International Advance Computing Conference. 2009.

[14]. Thalji, Z. and M. Alsmadi, Iris Recognition using robust algorithm for eyelid, eyelash and shadow avoiding. World Applied Sciences Journal, 2013. 25(6): p. 858-865.

[15]. Alsmadi, M., U.A. Badawi, and H.E. Reffat, A High Performance Protocol for Fault Tolerant Distributed Shared Memory (FaTP). Journal of Applied Sciences, 2013. 13: p. 790-799.

[16]. HADDAD, F., J. ALFARO, and M.K. ALSMADI, HOTELLING'S T² CHARTS USING WINSORIZED MODIFIED ONE STEP MESTIMATOR FOR INDIVIDUAL NON NORMAL DATA. Journal of Theoretical \& Applied Information Technology, 2015. 72(2): p. 215-226.

[17]. Haddad, F. and M.K. Alsmadi, Improvement of The Hotelling's T2 Charts Using Robust Location Winsorized One Step M-Estimator (WMOM). Journal of Mathematics (ISSN 10162526), 2018. 50(1): p. 97-112.

[18]. Alsmadi, M.K., U.A. Badawi, and H.M. Moharram, SERVER FAILURES ENABLED JAVASPACES SERVICE. Journal of Computer Science, 2014. 10(4): p. 671-679.

[19]. Alsmadi, M., Apparatus and method for lesions segmentation, 2018, US Patent App. 15/614,893.

[20]. Alsmadi, M.K., Facial expression recognition, 2018, Google Patents.

[21]. Aldaej, R., et al., Analyzing, Designing and Implementing a Web-Based Auction online System. International Journal of Applied Engineering Research, 2018. 13(10): p. 80058013. 
[22]. Almaimoni, H., et al., Developing and Implementing WEB-based Online Destination Information Management System for Tourism. International Journal of Applied Engineering Research, 2018. 13(10): p. 7541-7550.

[23]. Almrashdeh, I.A., et al., Requirement analysis for distance learning management system students in Malaysian universities. Journal of Theoretical and Applied Information Technology, 2011. 24(1): p. 17-27.

[24]. Alsmadi, M.k., K.B. Omar, and S.A. Noah, Proposed method to decide the appropriate feature set for fish classification tasks using Artificial Neural Network and Decision Tree. IJCSNS 2009. 9(3): p. 297-301.

[25]. Alsubaie, N., et al., Analyzing and Implementing an Online Metro Reservation System. International Journal of Applied Engineering Research, 2018. 13(11): p. 91989206.

[26]. Daniyah Alkhaldi, D.A., Hajer Aldossary, Mutasem k. Alsmadi, Ibrahim Al-Marashdeh, Usama A Badawi, Muneerah Alshabanah, Daniah Alrajhi, Developing and Implementing Web-based Online University Facilities Reservation System. International Journal of Applied Engineering Research, 2018. 13(9): p. 6700-6708.

[27]. Almarashdeh, i., et al., Real-Time Elderly Healthcare Monitoring Expert System Using Wireless Sensor Network International Journal of Applied Engineering Research, 2018. 13(6): p. 3517-3523.

[28]. Al Smadi, M.K.S., Fish Classification Using Perceptron Neural Network, 2007, Centre for Graduate Studies, Universiti Utara Malaysia.

[29]. Alsmadi, M.K. and U.A. Badawi, Pattern matching in Rotated Images Using Genetic Algorithm. Journal of King Abdulaziz
University Computing and Information 2017. 5: p. 53 - 59.

[30]. Aldossary, S., et al., ANALYZING, DESIGNING AND IMPLEMENTING A WEB-BASED COMMAND CENTER SYSTEM. International Research Journal of Engineering and Technology, 2019. 6(1): p. 1008-1019.

[31]. Sheikh, R.A., et al., Developing and Implementing a Barcode Based Student Attendance System. International Research Journal of Engineering and Technology, 2019. 6(1): p. 497-506.

[32]. Ali, S.A.S., et al., Determinants of deposit of commercial banks in Sudan: an empirical investigation (1970-2012). International Journal of Electronic Finance, 2019. 9(3): p. 230-255.

[33]. Eljawad, L., et al., Arabic Voice Recognition Using Fuzzy Logic and Neural Network. International Journal of Applied Engineering Research, 2019. 14(3): p. 651-662.

[34]. Al Smadi, A.M., et al., Accessing Social Network Sites Using Work Smartphone for Face Recognition and Authentication. Research Journal of Applied Sciences, Engineering and Technology, 2015. 11(1): p. 56-62.

[35]. Alsmadi, M., Facial recognition under expression variations. Int. Arab J. Inf. Technol., 2016. 13(1A): p. 133-141.

[36]. Alsmadi, M., K. Omar, and I. Almarashdeh, Fish Classification: Fish Classification Using Memetic Algorithms with Back Propagation Classifier2012: LAP LAMBERT Academic Publishing.

[37]. Alsmadi, M., et al., A hybrid memetic algorithm with back-propagation classifier for fish classification based on robust features extraction from PLGF and shape measurements. Information Technology Journal, 2011. 10(5): p. 944-954. 
[38]. Alsmadi, M., et al., Fish Recognition Based on Robust Features Extraction from Size and Shape Measurements Using Neural Network Journal of Computer Science, 2010. 6(10): p. 1088-1094.

[39]. Alsmadi, M.K., An efficient similarity measure for content based image retrieval using memetic algorithm. Egyptian Journal of Basic and Applied Sciences.

[40]. Alsmadi, M.K., Query-sensitive similarity measure for content-based image retrieval using meta-heuristic algorithm. Journal of King Saud University - Computer and Information Sciences.

[41]. Alsmadi, M.K., et al., FACE IMAGE RECOGNITION BASED ON PARTIAL FACE MATCHING USING GENETIC ALGORITHM. SUST Journal of Engineering and Computer Sciences (JECS), 2017. 18(1): p. 51-61.

[42]. Alsmadi, M.K., et al., Fish recognition based on robust features extraction from color texture measurements using back-propagation classifier. Journal of Theoritical and Applied Information Technology, 2010. 18(1).

[43]. Badawi, U.A. and M.K. Alsmadi, A GENERAL FISH CLASSIFICATION METHODOLOGY USING META-HEURISTIC ALGORITHM WITH BACK PROPAGATION CLASSIFIER. Journal of Theoretical \& Applied Information Technology, 2014. 66(3): p. 803-812.

[44]. Yousuf, M., et al., A Novel Technique Based on Visual Words Fusion Analysis of Sparse Features for Effective Content-Based Image Retrieval. Mathematical Problems in Engineering, 2018. 2018.

[45]. Saritha, R.R., V. Paul, and P.G. Kumar, Content based image retrieval using deep learning process. Cluster Computing, 2018: p. 1-14.

[46]. Alsmadi, M.K., K.B. Omar, and S.A. Noah, Fish recognition based on robust features extraction from size and shape measurements using back- propagation classifier. International Review on Computers and Software, 2010. 5(4): p. 489494.

[47]. Alsmadi, M.K., et al., Fish recognition based on robust features extraction from size and shape measurements using neural network. Journal of Computer Science, 2010. 6(10): p. 1088.

[48]. Alsmadi, M.K.S., et al., Fish recognition based on the combination between robust feature selection, image segmentation and geometrical parameter techniques using Artificial Neural Network and Decision Tree. arXiv preprint arXiv:0912.0986, 2009.

[49]. Alsmadi, M., K.B. Omar, and S.A. Noah, Back propagation algorithm: the best algorithm among the multi-layer perceptron algorithm. International Journal of Computer Science and Network Security, 2009. 9(4): p. 378-383.

[50]. Alsmadi, M., et al., Fish recognition based on robust features extraction from size and shape measurements using neural network. Information Technology Journal, 2009. 10(5): p. 427-434.

[51]. Farag, T.H., et al., Extended Absolute Fuzzy Connectedness Segmentation Algorithm Utilizing Region and Boundary-Based Information. Arabian Journal for Science and Engineering, 2017: p. 1-11.

[52]. Alsmadi, M.K., A hybrid Fuzzy C-Means and Neutrosophic for jaw lesions segmentation. Ain Shams Engineering Journal.

[53]. Badawi, U.A. and M.K.S. Alsmadi, A Hybrid Memetic Algorithm (Genetic Algorithm and Great Deluge Local Search) With BackPropagation Classifier for Fish Recognition International Journal of Computer Science Issues, 2013. 10(2): p. 348-356.

[54]. M, A., O. K, and N. S, Back Propagation Algorithm : The Best Algorithm Among the Multi-layer Perceptron Algorithm. 
International Journal of Computer Science and Network Security, 2009. 9(9): p. 378-383.

[55]. Sharma, M., G. Purohit, and S. Mukherjee, Information Retrieves from Brain MRI Images for Tumor Detection Using Hybrid Technique K-means and Artificial Neural Network (KMANN), in Networking Communication and Data Knowledge Engineering2018, Springer. p. 145-157.

[56]. Gao, Y., et al., An enhanced artificial bee colony optimizer and its application to multilevel threshold image segmentation. Journal of Central South University, 2018. 25(1): p. 107120.

[57]. Alsmadi, M.K., A hybrid firefly algorithm with fuzzy-C mean algorithm for MRI brain segmentation. American Journal of Applied Sciences, 2014. 11(9): p. 1676-1691.

[58]. Alsmadi, M.K., MRI brain segmentation using a hybrid artificial bee colony algorithm with fuzzy-c mean algorithm. Journal of Applied Sciences, 2015. 15(1): p. 100.

[59]. Alsmadi, M.K., A hybrid Fuzzy C-Means and Neutrosophic for jaw lesions segmentation. Ain Shams Engineering Journal, 2017.

[60]. Park, S.H. and K. Han, Methodologic Guide for Evaluating Clinical Performance and Effect of Artificial Intelligence Technology for Medical Diagnosis and Prediction. Radiology, 2018: p. 171920.

[61]. Kermany, D.S., et al., Identifying Medical Diagnoses and Treatable Diseases by ImageBased Deep Learning. Cell, 2018. 172(5): p. 1122-1131. e9.

[62]. Almarashdeh, I., Sharing instructors experience of learning management system: A technology perspective of user satisfaction in distance learning course. Computers in Human Behavior, 2016. 63: p. 249-255.
[63]. ALMARASHDEH, I., et al., AN OVERVIEW OF TECHNOLOGY EVOLUTION: INVESTIGATING THE FACTORS INFLUENCING NON-BITCOINS USERS TO ADOPT BITCOINS AS ONLINE PAYMENT TRANSACTION METHOD. Journal of Theoretical and Applied Information Technology, 2018. 96(13).

[64]. Almarashdeh, I., The important of service quality and the trust in technology on users perspectives to continues use of mobile services. Journal of Theoretical \& Applied Information Technology, 2018. 96(10).

[65]. Almarashdeh, I. and M. Alsmadi. Investigating the acceptance of technology in distance learning program. in Information Science and Communications Technologies (ICISCT), International Conference on. 2016. Tashkent Uzbekistan IEEE.

[66]. Almarashdeh, I. and M. Alsmadi. Heuristic evaluation of mobile government portal services: An experts' review. in 11th International Conference for Internet Technology and Secured Transactions (ICITST). 2016. IEEE.

[67]. Almarashdeh, I. and M.K. Alsmadi, How to make them use it? Citizens acceptance of $\mathrm{M}$ government. Applied Computing and Informatics, 2017. 13(2): p. 194-199.

[68]. Almarashdeh, I. and M.K. Alsmadi, Applied Computing and Informatics. 2017.

[69]. Almarashdeh, I., A. Althunibat, and N.F. Elias, Developing a Mobile Portal Prototype for Egovernment Services. Journal of Applied Sciences, 2014. 14(8): p. 791-797.

[70]. Almarashdeh, I., et al., E-Government for mobile societies-stocktaking of current trends and initiatives. Journal of Applied Sciences, 2013. 14(8): p. 104-111. 
[71]. Almarashdeh, I., et al., Development of an interactive learning management system for malaysian distance learning institutions. Middle East Journal of Scientific Research, 2013. 14(11): p. 1471-1479.

[72]. AlMarashdeh, I., et al., An Elite Pool-Based Big Bang-Big Crunch Metaheuristic for Data Clustering. Journal of Computer Science, 2018.

[73]. Almarashdeh, I., N. Sahari, and N. Mat Zin, Heuristic evaluation of distance learning management system interface, in International Conference on Electrical Engineering and Informatics 2011, IEEE: Bandung, Indonesia p. 1-6.

[74]. Almarashdeh, I., et al. Instructors acceptance of Distance Learning Management System. in International Symposium on Information Technology 2010 (ITSim 2010). 2010. Kuala Lumpur: IEEE.

[75]. Almarashdeh, I.A., et al. Distance learners acceptance of learning management system. in 2nd International Conference on Data Mining and Intelligent Information Technology Applications (ICMIA2010). 2010. Seoul, Korea: IEEE.

[76]. Almarashdeh, I.A., et al., Distance Learning Management System requirements From Student's Perspective. The international Journal of Theoretical and Applied Information Technology, 2011. 24(1).

[77]. Almarashdeh, I.A., N. Sahari, and N.A.M. Zin. Heuristic evaluation of distance learning management system interface. in Electrical Engineering and Informatics (ICEEI), 2011 International Conference on. 2011. IEEE.

[78]. Almarashdeh, I.A., et al., The Success of Learning Management System Among Distance Learners in Malaysian Universitie. Journal of Theoretical and Applied Information Technology, 2010. 21 (2): p. 80-91.
[79]. Almarashdeh, I.A., et al., THE SUCCESS OF LEARNING MANAGEMENT SYSTEM AMONG DISTANCE LEARNERS IN MALAYSIAN UNIVERSITIES. Journal of Theoretical \& Applied Information Technology, 2010. 21(2).

[80]. Almarashdeh, I.A., et al., Acceptance of learning management system: A comparison between distance learners and instructors. Advances in Information Sciences and Service Sciences, 2011. 3(5): p. 1-9.

[81]. Almarashdeh, I.A.E., Study of the Usability of Learning Management System Tool (Learning Care) of Postgraduate Students in University Utara Malaysia (UUM), 2007, Graduate School, Universiti Utara Malaysia.

[82]. Almrashdah, I.A., et al. Distance learners acceptance of learning management system. in Advanced Information Management and Service (IMS), 2010 6th International Conference on. 2010. IEEE.

[83]. Almrashdah, I.A., et al. Instructors acceptance of distance learning management system. in Information Technology (ITSim), 2010 International Symposium in. 2010. IEEE.

[84]. ALMRASHDEH, I.A., et al., DISTANCE LEARNING MANAGEMENT SYSTEM REQIUREMENTS FROM STUDENT'S PERSPECTIVE. Journal of Theoretical \& Applied Information Technology, 2011. 24(1).

[85]. Almrashdeh, I.A., et al. Instructor's success measures of Learning Management System. in Electrical Engineering and Informatics (ICEEI), 2011 International Conference on. 2011. IEEE.

[86]. Ibrahim Almarashdeh, M.K.A., Ghaith Jaradat, Ahmad Althunibat, Sami Abdullah Albahussain, Yousef Qawqzeh, Usama A Badawi, Tamer Farag, Looking Inside and Outside the System: Examining the Factors Influencing Distance Learners Satisfaction in 
Learning Management System. Journal of Computer Science, 2018. 14(4): p. 453-465.

[87]. Jaradat, G., M. Ayob, and I. Almarashdeh, The effect of elite pool in hybrid population-based meta-heuristics for solving combinatorial optimization problems. Applied Soft Computing, 2016. 44: p. 45-56.

[88]. Jaradat, G.M., et al., Hybrid Elitist-Ant System for Nurse-Rostering Problem. Journal of King Saud University-Computer and Information Sciences, 2018.

[89]. Rasmi, M., et al., Healthcare professionals' acceptance Electronic Health Records system: Critical literature review (Jordan case study). International Journal of Healthcare Management, 2018: p. 1-13.

[90]. Alsmadi, M.K., Forecasting River Flow in the USA Using a Hybrid Metaheuristic Algorithm with Back-Propagation Algorithm. Scientific Journal of King Faisal University (Basic and Applied Sciences), 2017. 18(1): p. 13-24.

[91]. Adeyemo, J., O. Oyebode, and D. Stretch, River Flow Forecasting Using an Improved Artificial Neural Network, in EVOLVE-A Bridge between Probability, Set Oriented Numerics, and Evolutionary Computation VI2018, Springer. p. 179-193.

[92]. Ahani, A., M. Shourian, and P.R. Rad, Performance Assessment of the Linear, Nonlinear and Nonparametric Data Driven Models in River Flow Forecasting. Water Resources Management, 2018: p. 1-17.

[93]. Poschmann, P., et al. Realization of ETA Predictions for Intermodal Logistics Networks Using Artificial Intelligence. in Interdisciplinary Conference on Production, Logistics and Traffic. 2019. Springer.

[94]. Arendt, R., A. Kopczyński, and P. Spychalski. Centralized and Distributed Structures of Intelligent Systems for Aided Design of Ship
Automation. in International Conference on Information Systems Architecture and Technology. 2017. Springer.

[95]. Fontoura, M., W. Pree, and B. Rumpe. UML-F: A modeling language for object-oriented frameworks. in European Conference on Object-Oriented Programming. 2000. Springer.

[96]. Teixeira, 1., et al. Analysis and design of a project management information system: practical case in a consulting company. in CENTERIS/ProjMAN/HCis. 2016.

[97]. Almarashdeh, I., et al., Development of an interactive learning management system for malaysian distance learning institutions. . Middle East Journal of Scientific Research, 14(11), . 10.5829/idosi.mejsr.2013.14.11.2339, 2013. 14(11): p. 1471-1479.

[98]. Rajagopal, D. and K. Thilakavalli, A Study: UML for OOA and OOD. International Journal of Knowledge Content Development \& Technology, 2017. 7(2): p. 5-20.

[99]. Torchiano, M., et al., Do UML object diagrams affect design comprehensibility? Results from a family of four controlled experiments. Journal of Visual Languages \& Computing, 2017. 41: p. 10-21.

[100].Dennis, A., B.H. Wixom, and D. Tegarden, Systems analysis and design: An object-oriented approach with UML2015: John wiley \& sons.

[101].Bello, S.I., et al., A University Examination Web Application Based on Linear-Sequential Life Cycle Model. 2017.

[102].Dick, J., E. Hull, and K. Jackson, Requirements engineering2017: Springer.

[103].Bhuiyan, M., F. Haque, and L. Shabnam, Integration of organisational models and UML Use Case diagrams. Journal of Computers, 2018. 13(1): p. 1-18. 
[104].Jurkiewicz, J. and J. Nawrocki, Automated events identification in use cases. Information and Software Technology, 2015. 58: p. 110-122.

[105].Almarashde, I., A. Althunibat, and N. Fazidah El, Developing a Mobile Portal Prototype for Egovernment Services. Journal of Applied Sciences, 2014. 14: p. 791-797.

[106].Al-Ghamdi, A., et al., Developing and Implementing a Web-Based Platform for Skills and Knowledge Exchange. International Journal of Scientific Research in Science and Technology (IJSRST), 2019. 6(3).

[107].Ibrahim, R., Formalization of the data flow diagram rules for consistency check. arXiv preprint arXiv:1011.0278, 2010.

[108].Begg, C. and T. Connolly, Database systems: A practical guide to design, implementation, and management, 2002, Addison-Wesley.

[109].Onuiri, E.E., et al., Intelligent Tourism Management System. American Scientific Research Journal for Engineering, Technology, and Sciences (ASRJETS), 2016. 18(1): p. 304315.

Cite this Article

Rawan Al-Theeb, Hessa Al-Tami, Hadeel Al-Johani, Asalah Al-Mutairi, Ibrahim Al-Marashdeh, Mutasem K. Alsmadi, Muneerah Alshabanah, Daniah Alrajhi, "Developing and Implementing A System for Shipping Companies Comparison", International Journal of Scientific Research in Science and Technology (IJSRST), Online ISSN : 2395-602X, Print ISSN : 2395-6011, Volume 6 Issue 4, pp. 57-70, JulyAugust 2019. Available at doi : https://doi.org/10.32628/IJSRST19649 Journal URL : http://ijsrst.com/IJSRST19649 